Long-term bowel function, quality of life and sexual function in patients with anorectal malformations treated during the PSARP era

\title{
Kyrklund, Kristiina
}

\section{7-10}

Kyrklund, K , Pakarinen, M P \& Rintala , R J 2017 , ' Long-term bowel function, quality of life and sexual function in patients with anorectal malformations treated during the PSARP era ' , Seminars in pediatric surgery. , vol. 26 , no. 5 , pp. 336-342 . https://doi.org/10.1053/j.sempedsurg.2017.09.01

http://hdl.handle.net/10138/298133

https://doi.org/10.1053/j.sempedsurg.2017.09.010

publishedVersion

Downloaded from Helda, University of Helsinki institutional repository.

This is an electronic reprint of the original article.

This reprint may differ from the original in pagination and typographic detail.

Please cite the original version. 


\title{
Long-term bowel function, quality of life and sexual function in patients with anorectal malformations treated during the PSARP era
}

\author{
Kristiina Kyrklund, MD, PhD, Mikko P. Pakarinen, MD, PhD, Risto J. Rintala, MD, PhD* \\ Department of Pediatric Surgery, Children's Hospital, Helsinki University Central Hospital, P O Box 281, FIN-00029 HUS, Finland
}

\section{A R T I C L E I N F O}

\section{Keywords:}

Anorectal malformations

Posterior sagittal anoplasty

Anterior sagittal anorectoplasty

Cutback anoplasty

Rectourethral fistula

Vestibular fistula

Perineal fistula

Anterior anus

Bowel function score

Long-term outcomes

\begin{abstract}
A B S T R A C T
Anorectal malformations are an important group of congenital anomalies that vary widely in their anatomical characteristics and complexity. Understanding the long-term functional outcomes after modern treatments, and how these compare to the general population, are essential for ensuring that patients receive optimal, evidence-based care. With increasing appreciation of the wider impact of the illness on patients and their families, minimizing social disability from fecal incontinence and enabling normal social integration from the outset are key management concerns. This review summarizes the current knowledge on the functional outcomes by type of malformation, reflecting on the literature, and our institutional experience over a follow-up period of nearly 30 years.
\end{abstract}

(c) 2017 Elsevier Inc. All rights reserved.

\section{Introduction}

Anorectal malformations (ARMs) affect between 1:2000 and $1: 2500$ births, ${ }^{1}$ comprising a heterogenous spectrum of malformations that vary considerably in their anatomical characteristics, complexity, and functional prognosis. To date, the outcomes for different types of ARMs and after various treatments have mostly been presented together in studies, making it difficult to extract prognostic information for individual patients. $^{2}$ Methods of assessment have also varied between series, and only a few studies have included comparison with healthy controls., ${ }^{2,3}$ It is established that problems with fecal incontinence and sexual dysfunction were common among patients treated for ARMs with 'traditional' operations such as sacroabdominal or sacroabdominoperineal repairs, ${ }^{4,5}$ impacting significantly on quality of life (QoL). ${ }^{6,7}$ The advent of posterior sagittal anorectoplasty (PSARP) in $1982^{8}$ largely modernized the surgical approach to 'high' ARMs by enabling access to the rectourogenital connection under direct vision for the first time. Anterior sagittal anorectoplasty (ASARP) later followed as a less invasive method for the treatment of vestibular fistula in females, ${ }^{9}$ and laparoscopic anorectal pull-through (LAARP) ${ }^{10}$ and laparoscopy-assisted techniques have since been developed for approaching high urethral fistulas. ${ }^{11}$

Evaluating the outcomes of current surgical treatments is essential for evidence-based practice and improving care

\footnotetext{
* Corresponding author.

E-mail address: risto.rintala@hus.fi (R.J. Rintala).
}

standards for patients. As the vast majority of ARM patients treated in modern care survive up to adulthood, ${ }^{12}$ the wider goals of management are reducing social disability from fecal incontinence or sexual dysfunction, and ensuring that patients are able to grow up having a decent quality of life. ${ }^{13}$ This communication is based on examination of the literature and on the controlled results of our institutional follow-up of 159 patients treated during the PSARP era. ${ }^{14-17}$

\section{Institutional approach to management}

In this communication, ARMs with an anal canal termination mostly within the EAS are referred to as mild ARMs: these are anterior anus (AA) in females and perineal fistula (PF)/anal stenosis (AS) in males. By severe ARMs, we refer to those types with a fistulous bowel termination outside the support of the EAS; these are perineal and vestibular fistula (PF/VF) in females, and rectourethral fistula (RUF) in males. The outcomes for complex cloacal malformations have recently been discussed elsewhere. ${ }^{18}$ The outcomes for rare/regional variants described in the Krickenbeck classification are also not entered into herein, but the principles of treatment are the same as for other types of ARMs.

Our approach to mild ARMs has been based on individualized, minimally invasive procedures. AA in females, the mildest of all ARMs, is managed entirely conservatively or with serial Hegar dilatations, if a degree of stenosis is present. ${ }^{14}$ Our approach to $\mathrm{PF}$ in males is simple anal cutback, usually on the first day of life. We excise obstructing median bar defects in association with AS, 
and incise complete anal membranes ( $<5 \%$ of cases). ${ }^{15}$ We have consistently practiced internal anal sphincter (IAS)-saving repairs for severe ARMs, defined as preservation of the distal part fistula or urogenital communication in the repair. We perform ASARP for females with PF/VF during the neonatal period and usually as a single-stage procedure, and PSARP for males with RUF following initial primary divided sigmoid colostomy around 2-3 months of age. We currently conserve the distal part of the EAS during PSARP. Laparoscopy is employed at our institution for mobilization of the bowel in high urogenital connections followed by sagittal repair, avoiding the need for a laparotomy. ${ }^{11}$ Postoperatively, patients undergo a standard anal dilatation program up to Hegar 14, following which any colostomies are closed, and systematic follow-up continues up to adulthood.

\section{Operative complications}

The reported incidence of neonatal colostomy-related complications in ARMs is $17-68 \%$, mainly relating to prolapse or stricture. ${ }^{2}$ Completely diverted sigmoid colostomies have the lowest incidence of complications, ${ }^{19}$ which was $8 \%$ in the authors' recent series. ${ }^{16,17}$ Single-stage repair of vestibular fistula (VF) in females with anterior sagittal anorectoplasty (ASARP) has been shown to be safe and feasible ${ }^{20,21}$ when it is performed during the neonatal period in otherwise well infants. In older patients, a colostomy is employed. Following ASARP, the risk of perineal wound complications is $5-15 \%,{ }^{16,20-22}$ and these are mostly superficial infections that respond well to local hygiene and antibiotics. ${ }^{2,16,20,21}$ Significant wound breakdown requiring re-suturing is uncommon $(2-3 \%){ }^{16,21}$

Most surgical complications following PSARP relate to minor mucosal ectopy or anal stenosis that are correctable with local procedures. ${ }^{12,17}$ Serious operative complications affect only $2 \%$ of patients, ${ }^{12,23}$ offering a significant safety advantage over classical operations where the risk was up to $30 \%{ }^{12}$ Prior to 1991 , when we performed PSARP after 6 months of rectal taperings due to significant dilatation were sometimes required, and were occasionally followed by rectal strictures. ${ }^{17}$ Since performing PSARP for RUF at 2-3 months of age, taperings have been necessary only exceptionally. Rectal prolapse occurs in 3\% of cases after PSARP, but remains a common complication following LAARP $(9-46 \%)^{17,24}$ that rectal fixation to the presacral fascia has attempted to address. $^{24}$ Posterior urethral diverticula also complicate incomplete excision of the fistula following laparoscopic dissection, ${ }^{25}$ particularly in bulbar cases.

In sagittal repairs, sufficient mobilization of the terminal bowel and fistula to achieve tension-free anastomosis to the center of the EAS, and prevention of damage to the posterior urethra in males and vaginal wall during dissection of VF are important technical points for avoiding iatrogenic complications. ${ }^{19,26}$ Most other late local complications after repair of ARMs are usually the result of insufficient follow-up and care, ${ }^{2}$ particularly with regard to the management of constipation. At our center, six resections of megarectum (4\%) were performed due to intractable constipation. ${ }^{16,17}$ Only one re-do ASARP has been required following gradual perineal body breakdown in one patient, ${ }^{16}$ and no revisions of PSARP among our primary cases, ${ }^{17}$ which supports the appropriateness of centralization of ARMs to specialist centers. Success of the primary operation largely determines the patient's chances of obtaining a good functional outcome, ${ }^{28}$ and secondary reconstructions have little to offer thereafter for most. In males with mild ARMs, we have avoided any urologic complications after cutback anoplasty. Minor revisional surgery has been required by $6 \%$ of males with mild ARMs on 1-2 occasions. ${ }^{15}$ In females with $\mathrm{AA}$, iatrogenic injuries are completely avoided with conservative management.

\section{Long-term bowel function}

\section{Fecal continence in mild ARMs}

The continence outcomes that are achieved in mild ARMs with systematic aftercare are thought to be good in most cases, ${ }^{12}$ and our institutional data fully supports this conclusion. The Rintala Bowel Function Score ${ }^{29}$ was used for the qualitative assessment of long-term fecal continence among 91 patients with mild ARMs. ${ }^{14,15}$ A normal score indicative of a good outcome was defined as a BFS of $\geq 17 / 20$, which was achieved by $\geq 90 \%$ of 594 controls from the same population. ${ }^{30}$ Over a median of 12 (range, 4-29) years, 93\% of AA females ${ }^{14}$ and $87 \%$ of males with mild ARMs ${ }^{15}$ had a BFS in the normal range, and no patient had a poor score $(<12)$. The median BFS among patients with mild ARMs was $19 / 20$ (range, 14-20), ${ }^{14,15}$ with no significant difference in the overall outcome compared to matched peers. ${ }^{14,15}$ Minor soiling $(<1 /$ week) occurred in approximately $1 / 3$ of both patients and controls (Table 1$).^{14,15}$ Among Finnish controls aged 4-7 years, soiling was reported by $50 \%$, reducing with age to approximately one quarter by adolescence. $^{30}$ Among patients with mild ARMs, there was no significant difference in any aspect of fecal continence in comparison to controls in the long term (Table 1). All patients with mild ARMs had achieved voluntary bowel movements (VBMs) and had weaned from diapers at the normal age. ${ }^{14,15}$ Furthermore, comparable proportions of patients with mild ARMs and matched peers reported both total continence (no soiling or fecal accidents), and social continence, defined as soiling or fecal accidents $<1 /$ week and no requirement for protective aids (Table 1). These findings are consistent with the good outcomes reported in other series ${ }^{1,23,31-34}$ that include patients after both cutback and PSARP. This clinical data supports the safety and appropriateness of minimally invasive treatments for the treatment of mild ARMs, and there is no suggestion to date that other treatments afford superior long-term functional results.

Table 1

Controlled results for prevalence of impairment of fecal control in mild ARMs after minimally invasive treatments after 12 (range, $4-29$ ) years of follow-up. ${ }^{14,15}$

\begin{tabular}{|c|c|c|c|c|c|c|c|}
\hline & \multirow[t]{2}{*}{$n$} & \multicolumn{4}{|c|}{ Total reporting any impairment, \% (\% impairment > 1/week) } & \multicolumn{2}{|c|}{ Continence } \\
\hline & & Rectal sensation & Witholding defecation & Soiling & Fecal accidents & \%Total & \%Social \\
\hline AA females & 45 & $7(0)$ & $6(2)$ & $31(2)$ & $9(0)$ & 69 & 98 \\
\hline Female controls & 135 & $4(1)$ & $4(0)$ & $34(0)$ & $3(0)$ & 64 & 100 \\
\hline Mild ARM males & 46 & $7(0)$ & $13(0)$ & $33(3)$ & $5(0)$ & 67 & 98 \\
\hline Male controls & 138 & $4(0)$ & $6(2)$ & $36(2)$ & $6(1)$ & 64 & 97 \\
\hline
\end{tabular}

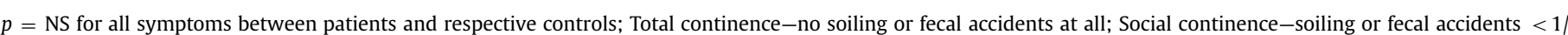
week and no requirement for protective aids 


\section{Fecal control in VF/PF females}

The minimally invasive nature of ASARP, which conserves of the posterior part of the EAS, makes it an attractive operation for the repair of PF and VF in females. Cutback anoplasty, the traditional operation for these ARMs, usually confers adequate continence up to adulthood, but in females this results in a 'gaping' anus with an anteriorly deficient EAS and greatly shortened perineal body that is cosmetically and hygienically suboptimal. ${ }^{16,35,36}$ Other operative techniques, including anal transposition, $\mathrm{Y}-\mathrm{V}$ plasty, and $\mathrm{X}-\mathrm{Z}$ plasty $^{35}$ have largely been superseded by sagittal repairs. ${ }^{16}$ The literature suggests that the vast majority of females with PF/VF do well in the long-term after sagittal repairs, with 93-100\% VBMs reported in recent series. ${ }^{16,20-22,34}$ 'Normal' continence was found in $71 \%$ of 67 patients in the series of Heinen, ${ }^{37}$ which concurs closely with the $68 \%$ with a BFS $\geq 17 / 20$, and median BFS of $18 / 20$ in the our recent series. ${ }^{16}$ Although these outcomes are mostly good, our data suggests that a proportion of patients may continue to experience deficiencies in the fine-tuning of fecal control in the long-term that is different from matched peers, as shown in Table $2 .{ }^{16}$ Fortunately, most symptoms are likely to be infrequent $(<1 /$ week) and poor outcomes are uncommon after ASARP (2-6\%). ${ }^{16,21}$ Successful centering of the anorectum fully within the support of the EAS may be associated with improved functional outcomes. ${ }^{26}$

The rates of complete continence among females with VF have varied between $41 \%$ and $65 \%$ in some series, ${ }^{16,34,38}$ to $98-100 \%$ in others. ${ }^{20,21,39}$ These are more likely to reflect methodological variations in the length of follow-up and depth of inquiry rather than substantial differences between experienced units. In the authors' series, "totally continent" patients includes only those patients who reported no soiling or fecal accidents whatsoever; if infrequent events ( $<1 /$ week) that were also common among our controls are disregarded, "total continence" rises to 85\% among VF/ PF patients and from $76 \%$ to $100 \%$ in controls. ${ }^{16}$ Validated methods of assessment and outcome reporting for ARMs by single type, gender, and after standardized treatments are therefore needed to obtain results that are consistent and comparable. Using an independent investigator to conduct the study, as in our institutional series, ${ }^{14-17}$ is also important to enable patients to disclose unfavorable results that they might not disclose to their own surgeon. To date, only one relatively small series has prospectively aimed to compare the outcomes following ASARP and PSARP for $\mathrm{PF} / \mathrm{VF}$ in females; this found no significant difference in the functional outcomes in the short-mid term, but suggested better cosmesis after ASARP. ${ }^{40}$

\section{Fecal continence in RUF males}

\section{Outcomes after classical repairs}

Preceding the PSARP era, the prevalence of soiling among patients with high urogenital connections treated with 'classical' repairs was $81-94 \%$, and $30-68 \%$ of patients had undergone some form of later secondary sphincter reconstruction for deficient continence. ${ }^{5,41,42,43}$ Nearly one third were more or less totally incontinent or had a permanent stoma, and $85 \%$ significant reported social disability. ${ }^{34}$ The current literature strongly favours improved continence outcomes after modern treatments. Compared to only $7.5 \%$ of patients with high ARMs after classical operations, ${ }^{1,44}$ total continence was reported in $35-36 \%$ of patients following PSARP for urethral fistula in two large series. ${ }^{23,29}$ The clear technical advantage of PSARP is repair of the malformation under direct vision, and precise repositioning of the bowel within the external sphincter funnel that was not possible with classical approaches due to intraoperative conservation of the puborectalis sling. ${ }^{26}$

\section{Other important prognostic factors}

Natively, the level of the anomaly impacts on the continence prognosis; males with rectobladderneck or vesical fistulas have a significantly worse functional outlook than bulbar urethral connections or females with $\mathrm{VF} / \mathrm{PF}^{16,17}$ due to greater hypoplasia of the sphincter musculature and associated structures. ${ }^{12,23}$ Other negative prognostic indicators are severe sacral anomalies ( $>2$ segments missing, hemisacrum, or total agenesis), meningomyelocele, and/or significant cognitive impairment. Mild sacral dysplasia (3-4 segments remaining) may not impact significantly on the prognosis for fecal continence, prevalence of lower urinary tract symptoms, or sexual function according to recent analyses. ${ }^{16,17,45}$ The presence of functional IAS on anorectal manometry, as indicated by a positive rectoanal inhibitory reflex (RAIR) postoperatively, has been associated with improved functional outcomes. $^{29,45}$ This finding favours conserving the distal part of the fistula in severe ARMs in association with sagittal repairs. RAIR was preserved in $100 \%$ of mild ARMs and $83 \%$ of severe ARMs (including 70\% of males with RUF after PSARP) in the authors' recent evaluation. ${ }^{45}$

\section{Fecal control after PSARP for RUF}

The continence outlook for males with RUF continues to be less optimistic than for milder types of ARMs. Although VBMS are established in $64-79 \%$ with modern management, ${ }^{17,23,46}$ soiling may continue to affect $70-82 \%$ of patients. ${ }^{17,29,46}$ Although our cross-sectional data showed that some soiling was common among RUF patients (Table 2), frequent impairment of any aspect of fecal control ( $>1$ /week) was less prevalent, reducing to $\leq 15 \%$ among patients with VBMs followed up for more than 12 years. ${ }^{17}$ This suggests considerably improved outcomes compared to classical repairs. Overall, a good functional outcome in the normal range (BFS $\geq 17$ ) was achieved in $39 \%$ of RUF patients in our series, and a clearly poor score (BFS $\leq 11$ ) in only $9 \% .{ }^{17}$

In our current assessment, no RUF males $<12$ years old were entirely free of soiling and fecal accidents on detailed questioning, ${ }^{17}$ and therefore no patients in this age group were deemed to

Table 2

Controlled results for prevalence of impairment of fecal control in VF/PF females and RUF after 12 (range, 4-29) years of follow-up from IAS-saving sagittal repair. ${ }^{16,17}$

\begin{tabular}{|c|c|c|c|c|c|c|c|}
\hline & \multirow[t]{2}{*}{$n$} & \multicolumn{4}{|c|}{ Total reporting any impairment, \% (\% impairment > 1/week) } & \multicolumn{2}{|c|}{ Continence } \\
\hline & & Rectal sensation & Witholding defecation & Soiling & Fecal accidents & \%Total & \%Social \\
\hline PF/VF females, ASARP & 34 & $15(6)$ & $26(6)^{a}$ & $59(15)^{\mathrm{a}}$ & $21(6)^{a}$ & $41^{\mathrm{a}}$ & $85^{a}$ \\
\hline Female controls & 102 & $7(0)$ & $2(0)$ & $24(0)$ & $2(0)$ & 76 & 100 \\
\hline RUF males, PSARP & 33 & $33(9)^{a}$ & $54(15)^{\mathrm{a}}$ & $70(18)^{\mathrm{a}}$ & $54(15)^{\mathrm{a}}$ & $30^{\mathrm{a}}$ & $76^{\mathrm{a}}$ \\
\hline Male controls & 99 & $9(n / a)$ & 5 (n/a) & 30 (n/a) & $6(n / a)$ & 73 & $96^{a}$ \\
\hline
\end{tabular}

${ }^{a} p<0.05$ vs respective controls for symptom; Total continence-no soiling or fecal accidents at all; Social continence-soiling or fecal accidents $<1 /$ week and no requirement for protective aids 
be completely continent. However, after $>12$ years of follow-up, $42 \%$ had VBMs and complete continence, and $21 \%$ reported no bowel symptoms whatsoever (BFS 20/20). ${ }^{17}$ Soiling and fecal accidents declined significantly with age from $100 \%$ for both (includes all eposodes) to $59 \%$ and $37 \%$, respectively beyond 12 years of age, and frequent episodes ( $>1$ /week) fell from $33 \%$ for both, to $13 \%$ for soiling and $8 \%$ for fecal accidents. ${ }^{17}$ In the longterm, several series have documented improving bowel function over time in patients with severe ARMs that is similar to ours. 17,29,47 However, it is unlikely that actual improvement in sphincter function occurs. ${ }^{17}$ Although the tendency to constipation also declines with age, ${ }^{3,17}$ a significant contribution from social adaptation is likely but difficult to quantify using surveys. These outcomes beyond adolescence are of great interest because they represent the functional endpoints beyond which any further improvements are unlikely. ${ }^{12}$ In the long-term, in our RUF patients followed up for 12-29 years after PSARP, $83 \%$ in total were socially continent (including 3 patients using ACE conduits), and 71\% were socially continent with VBMs (no requirement for artificial interventions). ${ }^{17}$ Information on the long-term outcomes following laparoscopic methods of repair for high ARMs is still accumulating, but there is no data to suggest that the continence outcomes are superior compared to PSARP. ${ }^{27}$

\section{Poor fecal control in RUF}

Among patients with RUF, there will be a proportion that will experience very poor fecal control, at least during childhood, usually from a combination of constipation and sphincter insufficiency. In these cases, our preference is to intervene early with ACE conduits to enable weaning from diapers and social integration before primary school, which is currently around the age of 4 years. In our experience, this offers a reversible and more acceptable route for bowel washouts in children than repeated rectal enemas. Social continence is restored in $2 / 3-95 \%,{ }^{2,17}$ and approximately $1 /$ 3 are able to undergo closure of the conduit with time. ${ }^{17}$ One quarter of our patients with RUF currently have ACE bowel management, including $44 \%$ of $4-12$-year-olds and $17 \%$ of adolescents and adults, reflecting this trend toward early intervention. ${ }^{17}$ Of these patients, who theoretically represent those with the worst functional outcomes, $75 \%$ are socially continent with no requirement for protective aids between washouts, and social problems did not specifically cluster among them. ${ }^{17}$ Relative to females with $\mathrm{VF} / \mathrm{PF}$, where only one patient has required an $\mathrm{ACE}^{16}$ and patients with mild ARMs, where none have required an $A C E,{ }^{14,15}$ the relative severity of RUF is nonetheless reflected.

\section{Continence prognosis by level of RUF}

The likelihood of requiring bowel management for defective continence is particularly likely the higher the level of the urogenital connection (Table 3), and this should be incorporated into care planning. The outcomes from our cross-sectional evaluation concur almost precisely with the outcomes from the large series of Levitt and Peña ${ }^{38}$ (Table 3 ). The largest series to date on boys with rectobladderneck fistula of 69 patients, ${ }^{48}$ also from Peña's group, identified a 75\% requirement for ACE bowel management in these patients, consistent with our data (Table 3). This highlights the need to prepare for secondary interventions to assure acceptable continence from early on in these cases. Unlike in mild ARMs and VF/PF females, where diapers for stool were discontinued at a median 2.2-2.5 (range, 1.1-4.0) years ( $p=$ NS vs controls for both boys and girls), ${ }^{14-16}$ weaning from diapers for stool is likely to be significantly delayed in RUF males [a median of 5 (range: $2.5-7.3$ ) years in our recent series] ${ }^{17}$ and may require ACE bowel management to achieve before school age (5/7 patients in our series). ${ }^{17}$ Prognostic counseling is therefore important so that parental expectations for the development of continence are reasonable and realistic, but also for instilling hope and motivation to participate in bowel management programmes, which can enable weaning from diapers and social continence in the majority of children.

\section{Constipation in ARMs}

The importance of effective management of constipation in the aftercare of ARM patients cannot be overemphasized. It has been suggested that constipation is more common after PSARP than after classical operations, and it is likely that this observation is accurate. Whereas the postoperative picture after classical operations for RUF was predominated by varying levels of fecal incontinence, ${ }^{1,44}$ the better continence outcomes after PSARP ${ }^{49}$ now mean that even patients with high ARMs have the 'opportunity' to develop constipation. It is likely that constipation in ARMs stems from abnormalities in the structural components of the rectal termination, ${ }^{34,50,51}$ which may be developmental and/or influenced by corrective surgery for the ARM. Our institutional data and the large series of Levitt and Peña, ${ }^{38}$ in which the prevalence is quantified for different types of ARMs, suggest that constipation affects all types of ARMs, as shown in Table 4. This observation has been consistently made in other series of patients treated during the PSARP era. ${ }^{2,29,38}$ Some accounts for variations in the prevalence of constipation between series is likely to come from different lengths of follow-up, as shown in Table 4. The exception is rectobladderneck fistula, where constipation is least likely due to poor sphincter function. Our data (Table 4) fully supports the observation that constipation in ARMs declines over time to levels that are no longer significantly different from those that are found in the general population ${ }^{1,3,47}$ and therefore carries a good prognosis when appropriately managed.

Our institutional practice involves a stepwise approach to the treatment, involving dietary modifications, oral laxatives and/or enemas as appropriate, but also includes open access to a nurse specialist for advice. Furthermore, keeping patients under regular outpatient follow-up, including those with mild ARMs, is essential for avoiding the severe consequences of untreated constipation. ${ }^{52}$

Table 3

Continence outcomes by level of fistula in RUF after PSARP.

\begin{tabular}{|c|c|c|c|c|c|c|c|c|}
\hline \multirow[t]{2}{*}{ Level of RUF } & \multirow[t]{2}{*}{$n$} & \multicolumn{2}{|c|}{ Levitt and Peña $(2005)^{38}$} & \multirow[t]{2}{*}{$n$} & \multicolumn{4}{|c|}{ Kyrklund et al. (2014), ${ }^{17}$ median 12 (4-29) years of follow-up } \\
\hline & & VBMs, \% & VBMs $+\mathrm{TC}, \%$ & & VBMs, \% & $\mathrm{VBMs}+\mathrm{TC}^{\mathrm{a}}, \%$ & Median BFS/20 & ACE, \% \\
\hline Bulbar & 83 & 82 & 41 & 12 & 92 & 42 & $18(6-20)$ & 8 \\
\hline Prostatic & 71 & 73 & 23 & 17 & 76 & 29 & $16(7-20)$ & 22 \\
\hline Bladderneck & 29 & 28 & 0 & 4 & 25 & 0 & $15(15)$ & 75 \\
\hline
\end{tabular}

VBMs, voluntary bowel movements; TC, total continence; BFS, bowel function score; ACE, antegrade continence enema conduit.

${ }^{a}$ Comparatively TC reported by $73 \%$ of matched controls, ${ }^{17}$ and by $65 \%$ of 594 controls aged $4-26$ years in the authors' earlier study. ${ }^{30}$ 
Table 4

Constipation by type of ARM and changes with age on prevalence.

\begin{tabular}{|c|c|c|c|c|c|c|}
\hline \multirow[t]{3}{*}{ ARM } & \multirow[t]{3}{*}{$n$} & \multicolumn{5}{|l|}{ Constipation, \% } \\
\hline & & \multirow{2}{*}{$\begin{array}{l}\text { Levitt and Peña }(2005)^{38} \\
\text { All patients }\end{array}$} & \multicolumn{4}{|c|}{ Kyrklund et al. (2014-2015) } \\
\hline & & & $n$ & All patients & Age $4-12$ years & Age $12-29$ years \\
\hline Anterior anus & $\mathrm{n} / \mathrm{a}$ & $\mathrm{n} / \mathrm{a}$ & 45 & 36 & 45 & 14 \\
\hline Perineal fistula & 53 & 56 & 46 & 33 & 45 & $12^{\mathrm{c}}$ \\
\hline Vestibular fistula & 100 & 61 & $34^{\mathrm{b}}$ & 44 & 59 & 25 \\
\hline Rectourethral fistula & 219 & $15-64^{a}$ & 33 & 31 & 44 & $13^{\mathrm{c}}$ \\
\hline
\end{tabular}

$15 \%$ in rectobladderneck fistula; $45 \%$ in prostatic fistula; $64 \%$ in bulbar fistula

${ }^{\mathrm{b}}$ Females with $\mathrm{VF} / \mathrm{PF}$.

${ }^{c} p<0.05$ vs $4-12$ years old.

Management of overflow incontinence, gross fecal impaction, and eventual megacolon requiring surgery is much less rewarding than simple primary prevention. In our experience, most constipation in ARMs responds adequately to oral laxatives, but regular dialog with patients and families is necessary for upholding compliance with treatment that usually needs to be continued for at least several years.

\section{Social problems and QoL}

Preventing social disability from an early age is fundamental in the management of ARMs. Social problems among the authors' cohort of patients with mild ARMs were uncommon $(\leq 3 \%)$, and gastrointestinal quality of life index (GIQLI) scores were entirely comparable to controls. ${ }^{14,15,53}$ These findings largely parallel the good/normal long-term continence outcomes that are achieved in these patients (Table 1) with appropriate aftercare. Among patients with severe ARMs, social problems affected 15-36\% with increasing severity of the ARM, and were severely limiting in 9\%. ${ }^{16,17}$ Patients who continue to experience significant social limitations in the long-term highlight the need for robust transitional care arrangements to enable continued medical care in adulthood. Such arrangements are not currently available in many centers.

More subtle problems relating to emotional functioning and negative body image have also been identified among ARM patients in recent series. ${ }^{53,54}$ These are likely to stem from negative childhood experiences and represent targets for focused multidisciplinary strategies to deal with illness perceptions. Early institution of bowel management programmes may substantially impact on such QoL outcomes by avoiding the consequences of social discrimination in the first instance. ${ }^{55,56,58}$ Fecal incontinence in children has also been shown to be particularly stressful to caregivers, and fostering coping strategies within families may be more important than has been previously appreciated. ${ }^{57}$

\section{Sexual function and fertility}

There is limited data available on the outcomes for sexual function and fertility among ARM patients treated exclusively during the PSARP era. After classical pull-through operations, significant erectile dysfunction affected up to $30 \%$ of patients. ${ }^{59,60}$ Damage to the pelvic nerves may be considerably less likely after PSARP owing to dissection under direct vision. ${ }^{59,61-63}$ In the authors' recent series, normal erections were reported by $90 \%$ of males after PSARP and erections sufficient for penetration by the remainder, and orgasmic function was also preserved. ${ }^{53}$ No sexual dysfunction was reported among males with low ARMs after simple cutback anoplsty, and females with VF/PF reported similar outcomes for domains of sexual function to matched controls after
ASARP. $^{53}$ Successful social integration in this respect was also suggested by a lack of differences in the proportion of patients in stable relationships or in the proportion with experience of sexual intercourse in relation to controls by type of ARM, including males with RUF. A later coital debut compared to controls, however, suggested some effect from the ARM on the willingness to commence intimate relationships that has also been reported by others. $^{59}$

Although intraoperative injuries to reproductive structures, such as an opened seminal vesicle or divided vas are reported in only $0.3-2 \%$ of cases after PSARP, it is likely that their actual incidence, particularly during dissection of high fistulas, is higher. ${ }^{61,62,64}$ In the authors' series, $11 \%$ of RUF males had absent ejaculations after PSARP, and a further patient had azoospermia on investigations for infertility (15\% of cases in total). ${ }^{17}$ Athough the ejaculatory abnormalities have been reported in $17-41 \%$ of patients after classical repairs for ARMs, ${ }^{59,60,62}$ formal ejaculate analysis would be needed to determine their actual prevalence after PSARP in RUF. As testicular maldescent affects up to $27 \%$ of patients with high ARMs, ${ }^{65}$ this may contribute to reduced fertility in some patients. Successful pregnancies have been reported among females with ARMs, ${ }^{36,59,62}$ with suggestion of no difference in fertility rates compared to the general population according to one series. ${ }^{60}$ Delivery by cesarean section is advocated in our institution after ASARP to avoid damage from childbirth to the repaired pelvic floor and sphincters.

\section{Conclusions}

The currently available data on the long-term outcomes of ARMs favours the use of minimally invasive treatments for mild ARMs with a bowel termination mostly within the EAS, and ASARP for the treatment of VF and PF in females. With appropriate aftercare that includes vigorous treatment of constipation, longterm continence outcomes within the normal range in comparison to matched peers from the general population can be achieved, whilst avoiding the risk of significant iatrogenic complications. In ARMs with a bowel termination outside the support of the EAS including PF and VF in females, and RUF in males, the use of anatomical repairs to restore the normal relationships between the bowel termination and the EAS are recommended. Constipation is a significant feature in ARMs, and maintaining patients under regular follow-up is important to ensure compliance with treatment and prevention of secondary complications. The functional outcomes following PSARP for RUF are considerably better than those observed after classical pull-through operations in terms of both fecal control and sexual function, but potential fertility issues require further characterization. Although the majority of patients with severe ARMs achieve social continence with modern treatments, the impairment of fecal control persists significant proportion of cases into adulthood, and assuring continuity of medical 
care is important in these cases. The literature on QoL after modern treatments suggests acceptable social integration among patients, but experiences of discrimination in childhood may be reflected in domains of emotional functioning. The early institution of bowel management programmes to reduce disability and to enable social continence before primary school, and multidisciplinary interventions for improving coping strategies within families may impact further on the QoL of these patients.

\section{References}

1. Rintala R, Lindahl H, Louhimo I. Anorectal malformations-results of treatment and long-term follow-up of 208 patients. Pediatr Surg Int. 1991;6:36-41.

2. Pakarinen MP, Rintala RJ. Management and outcome of low anorectal malformations. Pediatr Surg Int. 2010;26:1057-1063.

3. Rintala RJ, Lindahl HG. Fecal continence improves in patients having undergone posterior sagittal anorectoplasty procedure for a high anorectal malformation improves at adolescence, as constipation disappears. J Pediatr Surg. 2001;36: $1218-1221$.

4. Rintala R, Mildh L, Lindahl H. Faecal continence and quality of life in adult patients with an operated low anorectal malformation. J Pediatr Surg. 1992; 27:902-905.

5. Rintala R, Mildh L, Lindahl H. Fecal continence and quality of life for adult patients with an operated high or intermediate anorectal malformation. J Pediatr Surg. 1994:29:777-780.

6. Grano C, Aminoff D, Lucidi F, et al. Long-term disease-specific quality of life in adult anorectal malformation patinents. J Pediatr Surg. 2011;46:691-698.

7. Iwai N, Eiichi D, Kimura O, et al. Social quality of life for adult patients with anorectal malformations. J Pediatr Surg. 2007;42:313-317.

8. De Vries PA, Peña A. Posterior sagittal anorectoplasty. J Pediatr Surg. 1982;17: 638-643.

9. Okada A, Tamada $\mathrm{H}$, Tsuji $\mathrm{H}$, et al. Anterior sagittal anorectoplasty for rectovestibular and anovestibular fistula. J Pediatr Surg. 1992;27:85-88.

10. Georgeson K, Inge TH, Albanese CT. Laparoscopic-assisted anorectal pull-through for high imperforate anus-a new technique. J Pediatr Surg. 2000:35:927-930.

11. Liem NT, Quynh TA. Combined laparoscopic and modified posterior sagittal approach saving the external sphincter for urethral fistula: an easier and more physiologic approach. J Pediatr Surg. 2013;48:1450-1453.

12. Rintala RJ, Pakarinen MP. Imperforate anus: long- and short-term outcome. Semin Pediatr Surg. 2008;17:79-89.

13. Iwai N, Fumino S. Surgical treatment of anorectal malformations. Surg Today. 2013;43:955-962.

14. Kyrklund K, Pakarinen MP, Taskinen S, Rintala RJ. Bowel function and lower urinary tract symptoms in females with anterior anus treated conservatively: controlled outcomes into adulthood. J Pediatr Surg. 2015;50:97-103.

15. Kyrklund K, Pakarinen MP, Taskinen S, Rintala RJ. Bowel function and lower urinary tract symptoms in males with low anorectal malformations: an update of controlled-long-term outcomes. Int J Colorectal Dis. 2015;30:221-228.

16. Kyrklund K, Pakarinen MP, Koivusalo A, Rintala RJ. Bowel functional outcomes in females with perineal or vestibular fistula treated with anterior sagittal anorectoplasty: controlled results into adulthood. Dis Col Rectum. 2015;58:97-103.

17. Kyrklund K, Pakarinen MP, Koivusalo A, Rintala RJ. Long-term bowel functional outcomes in rectourethral fistula treated with PSARP: controlled results after 4-29 years of follow-up. J Pediatr Surg. 2014;49:1635-1642.

18. Rintala RJ. Congenital cloaca: long-term follow-up results with emphasis on outcomes. Semin Pediatr Surg. 2016:25:112-116.

19. Bischoff A, Levitt MA, Pena A. Update on the management of anorectal malformations. Pediatr Surg Int. 2013;29:899-904.

20. Wakhlu A, Kureel SN, Tandon RK, Wakhlu AK. Long-term results of anterior sagittal anorectoplasty for the treatment of vestibular fistula. I Pediatr Surg. 2008;44:1913-1919.

21. Kumar B, Kandpal DK, Sharma SB, Agarwal LD, Jhamiraya VN. Single-stage repair of vestibular and perineal fistulae without colostomy. J Pediatr Surg. 2008;43:1818-1952.

22. Kuijper CF, Aronson DC. Anterior or posterior sagittal anorectoplasty without colostomy for low-type anorectal malformations: how to get a better outcome. J Pediatr Surg. 2010;45:1505-1508.

23. Peña A. Anorectal malformations. Semin Pediatr Surg. 1995;4:35-47.

24. Yazaki Y, Koga H, Ochi T, et al. Surgical management of recto-prostatic and recto-bulbar anorectal malformations. Pediatr Surg Int. 2016;32:939-944.

25. Yamataka A, Lane GJ, Koga H. Laparoscopy-assisted surgery for male imperforate anus with rectourethral fistula. Pediatr Surg Int. 2013;29: 1007-1011.

26. Morandi A, Borzani I, Machhini F, Brisighelli G, Consonni D, Leva E. Correlation between magnetic resonance imaging findings after posterior sagittal anorectoplasty for anorectal malformations and the clinical outcome: preliminary report. J Pediatr Surg. 2016;51:1859-1863.

27. Bischoff A, Levitt MA, Pena A. Laparoscopy and its use in the repair of anorectal malformations. J Pediatr Surg. 2011;46:1609-1617.

28. Levitt MA, Peña A. In: Holschneider AM, Hutson JM, editors. Anorectal Malformations in Children: Embryology, Diagnosis, Surgical Treatment, Followup. Berlin, Germany: Springer-Verlag Publ; 2006. p. 319-325.
29. Rintala RJ, Lindahl $H$. Is normal bowel function possible after repair of high anorectal malformations? J Pediatr Surg. 1995;30:491-494.

30. Kyrklund K, Koivusalo A, Rintala RJ, Pakarinen MP. Evaluation of bowel function and fecal continence in 594 Finnish individuals aged 4 to 26 years. Dis Col Rectum. 2012;55:671-676.

31. Rintala RJ. Congenital anorectal malformations: anything new? J Pediatr Gastroenterol Nutr. 2009;48:S79-S82.

32. Yeung CK, Kiely EM. Low anorectal anomalies: a critical appraisal. Pediatr Surg Int. 1991;6:333-335.

33. Pakarinen MP, Koivusalo A, Lindahl H, Rintala RJ. Prospective controlled long term follow-up for functional outcome after anoplasty for boys with perinea fistula. J Pediatr Gastroenterol Nutr. 2007;44:436-439.

34. Peña A, Hong A. Advances in the management of anorectal malformations Am J Surg. 2000;180:370-376.

35. Javid PJ, Barnhart DC, Hirschi RB, et al. Immediate and long-term results of surgical management of low imperforate anus in girls. J Pediatr Surg. 1998;33: 198-203.

36. De Blaaw I, Midrio P, Breech L, et al. Treatment of adults with unrecognized or inadequately repaired anorectal malformations: 17 cases of rectovestibular and rectoperineal fistulas. I Pediatr Adolesc Gynecol. 2013;26: $156-160$.

37. Heinen FL. The surgical treatment of low anal defects and vestibular fistulas Semin Pediatr Surg. 1997:6:204-216.

38. Levitt MA, Pena A. Outcomes from the correction of anorectal malformations Curr Opin Pediatr. 2005;17:394-401.

39. Menon P, Rao KL. Prinary anorectoplasty infemales with common anorectal malformations without colostomy. J Pediatr Surg. 2007;42:1103-1106.

40. Shebata SM. Prospective long-term functional and cosmetic results of ASARP versus PSARP in treatment of intermediate anorectal malformations in girls. Pediatr Surg Int. 2009;25:863-868.

41. Hassink EA, Rieu PN, Severijnen RS, vand der Staak FH, Festen C. Are adults content or continent after repair for high anal atresia? A long-term follow-up study in patients 18 years of age and older. Ann Surg. 1993;218: 196-200.

42. Nixon HH, Puri P. The results of treatment of anorectal anomalies: a thirteen to twenty year follow-up. J Pediatr Surg. 1977;12:27-37.

43. Rintala RJ. In: Holschneider AM, Hutson JM, editors. Anorectal Malformations in Children: Embryology, Diagnosis, Surgical Treatment, Follow-up. Berlin, Germany: Springer-Verlag Publ; 2006. p. 361-376.

44. Taylor I, Duthie HL, Zachary RB. Anal continence following surgery for imperforate anus: a long-term follow-up investigation. J Pediatr Surg. 1973;8: 35-39.

45. Kyrklund K, Pakarinen MP, Rintala RJ. Manometric findings in relation to functional outcomes in different types of anorectal malformations. Sep 2. pii: S0022-3468(16)30301-3. http://dx.doi.org/10.1016/j.jpedsurg.2016.08.025. [Epub ahead of print].

46. Bliss DP, Tapper D, Anderson JM, et al. Does posterior sagittal anorectplasty in patients with high imperforate anus provide superior fecal continence? J Pediatr Surg. 1996;31:26-32.

47. Borg HC, Holmdahl G, Gustavsson K, Doroszkiewicz, Sillén U. Longitudinal study of bowel function in children with anorectal malformations. J Pediatr Surg. 2013;48:597-606

48. Samuk I, Bischoff A, Hall J, Levitt MA, Peña A. Anorectal malformation with rectobladderneck fistula: a distinct and challenging malformation. J Pediatr Surg. 2016;51:1592-1596.

49. Danielson J, Karlbom U, Graf W, Olsen L, Wester T. Posterior sagittal anorectoplasty results in better bowel function and quality of life in adulthood than pull-through procedures. J Pediatr Surg. 2015;50:15561559.

50. Rintala RJ, Marttinen E, Virkola K, Rasanen M, Baillie C, Lindahl H. Segmental colonic mortality in patients with anorectal malformations. J Pediatr Surg. 1997; 32(32):453-456.

51. Van Meegdeburg MM, Heineman E, Broens PMA. Dyssynergic defecation may aggravate constipation: results of mostly pediatric cases with congenital anorectal malformations. Am J Surg. 2015;210:357-364.

52. Levitt MA, Kant A, Pena A. The morbidity of constipation in patients with anorectal malformations. I Pediatr Surg. 2010;45:1228-1233.

53. Kyrklund K, Taskinen S, Rintala RJ, Pakarinen MP. Sexual function, fertility and quality of life after modern treatment of anorectal malformations. J Urol. 2016. Aug 18, pii: S0022-5347(16)31065-5. http://dx.doi.org/10.1016/j.juro.2016. 08.079 [Epub ahead of print]

54. Grano C, Bucci S, Aminoff D, Lucidi F, Violani C. Transition from childhood to adolescence: quality of life changes 6 years later in patients born with anorecta malformations. Pediatr Surg Int. 2015:31:735-740.

55. Grano C, Aminoff D, Lucidi F, Violani C. Long-term disease-specific quality of life in children and adolescent patients with ARM. J Pediatr Surg. 2012;47: $1317-1322$.

56. Bischoff A, Levitt MA, Bauer C, et al. Treatment of fecal incontinence with a comprehensive bowel management program. J Pediatr Surg. 2009;44: 1278-1284.

57. Cushing CC, Martinez-Leo B, Pena A, Bischoff A, Hall J, et al. Health-related quality of life and parental stress in fecal incontinence: a normative comparison. J Pediatr Gastroenterol Nutr. 2016 [Epub ahead of print].

58. Lombardi L, Garrisi E, Ricco M, et al. Study of intestinal function in anorecta malformations: the role of bowel management in quality of life. Acta Biomed. 2016;87(2):197-204. 
59. Schmidt D, Winter S, Jenetzky E, et al. Sexual function in adults with anorectal malformation: psychosocial adaptation. German Network for Congenital UroREctal Malformations (CURENet). Pediatr Surg Int. 2012;28:789.

60. Mantoo S, Meurette G, Wyart V, et al. The impact of anorectal malformations on anorectal function and social integration in adulthood: report from a national database. Colorectal Dis. 2013;15:e330.

61. Hong AR, Acuña MF, Peña A, et al. Urologic injuries associated with repair of anorectal malformations in male patients. J Pediatr Surg. 2002;37:339.
62. Konuma K, Ikawa H, Kohno M, et al. Sexual problems in male patients older than 20 years with anorectal malformations. J Pediatr Surg. 2006:41:306.

63. Misra D, Chana J, Drake DP, et al. Operative trauma to the genitourinary tract in the treatment of anorectal malformations: 15 years' experience. Urology. 1996;47:559.

64. Holt B, Pryor JP, Hendry WF. Male infertility after surgery for imperforate anus. J Pediatr Surg. 1995;30:1677.

65. McLorie GA, Sheldon CA, Fleisher M, et al. The genitourinary system in patients with imperforate anus. J Pediatr Surg. 1987;22:1100. 